\section{Dr. Pincus replies}

\section{To the Editor:}

We thank Dr. Kirwan for his usual thoughtful and imaginative observations. Considerable variation is also seen beyond physician global assessment in all rheumatoid arthritis (RA) core data set measures. Swollen and tender joint counts performed by a health professional vary widely ${ }^{1-4}$. Patient questionnaire scores for physical function, pain, global status, and fatigue vary in their ratios in different patients ${ }^{5,6}$, with patterns according to ethnic group ${ }^{7}$, indicating that patient perceptions also may vary considerably. Indeed, the different ratios have been suggested to provide clues to recognition of somatization ${ }^{5,6}$. All measurement is indeed associated with error and variation.

Our report ${ }^{8}$ was not directed to assess measurement variation and error, but rather to assess the relative efficiency of each of the 7 core data set measures to distinguish active from control treatments in clinical trials. This matter was of interest because most rheumatologists do not perform formal quantitative swollen and tender joint counts at most visits outside clinical trials ${ }^{9}$ and situations in which this is required (for biological therapies, for example). A joint count requires 90 seconds for performance, while a routine assessment of patient index data 3 (i.e., the RAPID3), an index of only patient questionnaire measures, requires only 10 seconds to score $^{10}$, and is highly correlated with the Disease Activity Score (DAS28) in clinical trials ${ }^{11}$ and clinical care ${ }^{12}$.

The joint count is weighted as more important than patient questionnaire or global measures in the RA core data $\operatorname{set}^{13}$, the DAS2 $8^{14}$, and the Clinical Disease Activity Index ${ }^{15}$. This higher weighting does not appear to be supported by statistical evidence in our studies ${ }^{8,11,12}$ and others ${ }^{16-18}$. However, it may well be argued that the specificity and comprehensiveness of joint counts would justify higher weighting in documenting differences between active and control treatment in clinical trials and changes in clinical care.

The goal "to develop a policy on judging severity of RA based on the collective opinions of many rheumatologists, as applied to substantial management decisions, such as when to change DMARD due to perceived lack of efficacy," as suggested by Dr. Kirwan, is laudable. However, in view of considerable variation in swollen and tender joint counts, despite extensive guidelines regarding their performance, perhaps such a policy might not necessarily be effective. Few studies in the literature define the measurement and psychometric properties of a physician global estimate compared to all other RA core data set measures on questionnaires, laboratory tests, or joint counts. Perhaps that suggests that the approach to a "policy" may be limited.

One reason that patient questionnaire scores appear quite robust is that a patient is a single observer, and any interaction with a health professional necessarily introduces a second observer and variation in measurement. The patient serves as his or her own control, thus reducing measurement error and variation - and management can be effective even without patient visits, as documented in elegant studies by Hewlett and Kirwan ${ }^{19,20}$.

More knowledge concerning variation and efforts to reduce this variation is desirable. Nonetheless, the primary point of our report was that the joint counts did not have greater value than other core data set measures to distinguish active from control treatments.

THEODORE PINCUS, MD, Division of Rheumatology, New York University School of Medicine and NYU Hospital for Joint Diseases, 301 East 17th Street, Room 1608, New York, NY 10003, USA. Address reprint requests to Dr. Pincus; E-mail: tedpincus@gmail.com

\section{REFERENCES}

1. Lewis PA, O’Sullivan MM, Rumfeld WR, Coles EC, Jessop JD. Significant changes in Ritchie scores. Br J Rheumatol 1988; 27:32-6.

2. Hart LE, Tugwell P, Buchanan WW, Norman GR, Grace EM, Southwell D. Grading of tenderness as a source of interrater error in the Ritchie articular index. J Rheumatol 1985;12:716-7.

3. Thompson PW, Hart LE, Goldsmith CH, Spector TD, Bell MJ, Ramsden MF. Comparison of four articular indices for use in clinical trials in rheumatoid arthritis: patient, order and observer variation. J Rheumatol 1991;18:661-5.

4. Klinkhoff AV, Bellamy N, Bombardier C, et al. An experiment in reducing interobserver variability of the examination for joint tenderness. J Rheumatol 1988;15:492-4.

5. Callahan LF, Pincus T. The P-VAS/D-ADL ratio: A clue from a self-report questionnaire to distinguish rheumatoid arthritis from noninflammatory diffuse musculoskeletal pain. Arthritis Rheum 1990;33:1317-22.

6. DeWalt DA, Reed GW, Pincus T. Further clues to recognition of patients with fibromyalgia from a simple 2-page patient Multidimensional Health Assessment Questionnaire (MDHAQ). Clin Exp Rheumatol 2004;22:453-61.

7. Yazici Y, Sokka T, Ricciardi DD, Pincus T. Differences in clinical status measures in different ethnic/racial groups with rheumatoid arthritis: implications for interpretation of clinical trial data. J Rheumatol 2007;34:311-5.

8. Pincus T, Amara I, Segurado OG, Bergman M, Koch GG. Relative efficiencies of physician/assessor global estimates and patient questionnaire measures are similar to or greater than joint counts to distinguish adalimumab from control treatments in rheumatoid arthritis clinical trials. J Rheumatol 2008;35:201-5.

9. Pincus T, Segurado OG. Most visits of most patients with rheumatoid arthritis to most rheumatologists do not include a formal quantitative joint count. Ann Rheum Dis 2006;65:820-2.

10. Yazici Y, Bergman M, Pincus T. Time to score quantitative rheumatoid arthritis measures: 28-joint count, Disease Activity Score, Health Assessment Questionnaire (HAQ), multidimensional HAQ (MDHAQ), and Routine Assessment of Patient Index Data (RAPID) scores. J Rheumatol 2008;35:603-9.

11. Pincus T, Bergman MJ, Yazici Y, Hines P, Raghupathi K, Maclean $R$. An index of only patient-reported outcome measures, Routine Assessment of Patient Index Data 3 (RAPID3), in two abatacept clinical trials: similar results to disease activity score (DAS28) and other RAPID indices that include physician-reported measures. Rheumatology Oxford 2008;47:345-9.

12. Pincus T, Swearingen CJ, Bergman M, Yazici Y. RAPID3 (Routine Assessment of Patient Index Data 3), a rheumatoid arthritis index without formal joint counts for routine care: Proposed severity categories compared to DAS and CDAI categories. J Rheumatol 2008; 35:2136-47.

13. Felson DT, Anderson JJ, Boers M, et al. The American College of Rheumatology preliminary core set of disease activity measures for rheumatoid arthritis clinical trials. Arthritis Rheum 1993; 36:729-40.

14. Prevoo MLL, van 't Hof MA, Kuper HH, van Leeuwen MA, van de Putte LBA, van Riel PLCM. Modified disease activity scores that include twenty-eight-joint counts: Development and validation in a prospective longitudinal study of patients with rheumatoid arthritis. Arthritis Rheum 1995;38:44-8.

15. Aletaha D, Smolen J. The Simplified Disease Activity Index (SDAI) and the Clinical Disease Activity Index (CDAI): a review of their usefulness and validity in rheumatoid arthritis. Clin Exp Rheumatol 2005;23:S100-S108.

16. Strand V, Tugwell P, Bombardier C, et al. Function and healthrelated quality of life: Results from a randomized controlled trial of leflunomide versus methotrexate or placebo in patients with active rheumatoid arthritis. Arthritis Rheum 1999;42:1870-8.

17. Tugwell P, Wells G, Strand V, et al. Clinical improvement as reflected in measures of function and health-related quality of life following treatment with leflunomide compared with methotrexate in patients with rheumatoid arthritis: Sensitivity and relative 
efficiency to detect a treatment effect in a twelve-month, placebocontrolled trial. Arthritis Rheum 2000;43:506-14.

18. Cohen SB, Strand V, Aguilar D, Ofman JJ. Patient- versus physician-reported outcomes in rheumatoid arthritis patients treated with recombinant interleukin-1 receptor antagonist (anakinra) therapy. Rheumatology Oxford 2004;43:704-11.

19. Hewlett S, Mitchell K, Haynes J, Paine T, Korendowych E, Kirwan JR. Patient-initiated hospital follow-up for rheumatoid arthritis. Rheumatology Oxford 2000;39:990-7.

20. Hewlett S, Kirwan J, Pollock J, et al. Patient initiated outpatient follow up in rheumatoid arthritis: six year randomised controlled trial. BMJ 2005;330:171-4.

J Rheumatol 2009;36:2; doi:10.3899/jrheum.081066 